\title{
The molecular basis of fertilization (Review)
}

\author{
KATERINA GEORGADAKI ${ }^{1}$, NIKOLAS KHOURY ${ }^{1}$, DEMETRIOS A. SPANDIDOS ${ }^{2}$ and VASILIS ZOUMPOURLIS ${ }^{1}$ \\ ${ }^{1}$ Institute of Biology, Medical Chemistry and Biotechnology, National Hellenic Research Foundation, \\ Athens 116 35; ${ }^{2}$ Laboratory of Clinical Virology, School of Medicine, University of Crete, Heraklion 71003, Greece
}

Received April 13, 2016; Accepted August 2, 2016

DOI: $10.3892 /$ ijmm.2016.2723

\begin{abstract}
Fertilization is the fusion of the male and female gamete. The process involves the fusion of an oocyte with a sperm, creating a single diploid cell, the zygote, from which a new individual organism will develop. The elucidation of the molecular mechanisms of fertilization has fascinated researchers for many years. In this review, we focus on this intriguing process at the molecular level. Several molecules have been identified to play a key role in each step of this intriguing process (the sperm attraction from the oocyte, the sperm maturation, the sperm and oocyte fusion and the two gamete pronuclei fusion leading to the zygote). Understanding the molecular mechanisms of the cell-cell interactions will provide a better understanding of the causes of fertility issues due to fertilization defects.
\end{abstract}

\section{Contents}

1. Introduction

2. Molecules synthesized and secreted from the oocyte, which orient and stimulate sperm

3. The three stages of fertilization

4. Reorganization and partition of the zygote

5. Fertilization failure

\section{Introduction}

Fertilization is a sequence of coordinated molecular events involving the merging of the sperm with the egg, the fusion of the pronuclei and the intermingling of the maternal and paternal chromosomes. The first form of human life is the

Correspondence to: Dr Vasilis Zoumpourlis, Institute of Biology, Medical Chemistry and Biotechnology, National Hellenic Research Foundation, 48 Vassileos Constantinou Avenue, Athens 116 35, Greece

E-mail:vzub@eie.gr

Key words: fertilization, zygote, gamete fusion, sperm capacitation, cortical reaction zygote (a diploid cell) from which the new organism will result. During sexual intercourse, millions of sperm are deposited into the vagina. A number of these will die in the acidic environment. However, many will survive due to the protective elements provided in the fluids surrounding them. Soon afterwards, the sperm have to swim through the cervical mucus, towards to the uterus and then on to the fallopian tubes. As they swim towards these, they decrease in number, in an attempt to make it through the mucus. Inside the uterus, the contractions of the uterus assist the journey of the sperm towards the egg. Fertilization takes place in the ampulla of the oviduct. If the oocyte is not fertilized here, it slowly passes to the uterus, where it becomes degenerated and is absorbed. Achieving fertilization requires the activation of sperm and oocyte maturation. However, the oocyte/sperm interaction depends on a number of changes occurring in the egg and the sperm.

The egg complex following ovulation enters the oviduct consisting of three components: i) the oocyte (egg) arrested at metaphase of meiosis II; ii) the extracellular matrix of the egg or zona pellucida consisting of three glycoproteins (ZP1, ZP2 and ZP3), synthesized and secreted by the oocyte; iii) the cumulus oophorus, consisting of granulosa cells enriched with hyaluronic acid $(1,2)$. Cumulus cells support fertilization, and in vitro fertilization can be achieved more efficiently with them than without them (3-5).

The journey of the sperm is facilitated by ovarian hormones that affect the structure, composition and activity of the secretory epithelia of the cervix, the uterus and the fallopian tubes and the contractility of these elements. The estrogen hormones, favor these factors, while progesterone does not. Oxytocin, which is secreted during intercourse by stimulation of the posterior pituitary, causes the contraction of the uterus and the fallopian tubes, as well as by the prostaglandins that affect the contractility of the uterus and fallopian tubes. During the ovulation period, the uterus becomes more sensitive to prostaglandins.

Oocytes acquire the ability to fuse with sperm when they reach $20 \mu \mathrm{m}$ in diameter and they are arrested at the prophase of meiosis II (6). Spermatozoa undergo a series of events during maturation in order to acquire motility and fertility, as they move from the proximal towards the distal end of the epididymis. Only spermatozoa that have passed through the epididymis are mature enough to be capable of motility. Moreover, via deposition of new proteins in the nucleus, the DNA becomes more condensed. The sperm head decreases in size and becomes more compact. The above is crucial for the subsequent correct 
decondensation of the paternal DNA in the maternal oocyte. The ability for motility is achieved, but at the same time is inhibited by the milieu. Finally, the structure of the plasma membrane is altered by the addition of glycoproteins and other proteins. This affects the motility, the capacitation ability and the ability for the acrosome reaction (http://www.embryology. ch/anglais/dbefruchtung/bereitstell02.html\#genitaltrakt).

Sperm is the male gamete and is derived from the Greek word 'sperma' (meaning 'seed'). It consists of three parts, a head (containing DNA and enzymes in order to penetrate the oocyte), a midpiece (containing cellular elements, centrioles, microtubules and a number of mitochondria for energy production required to promote sperm) and a tail (enabling sperm movement) (http://www.newworldencyclopedia.org/entry/ Sperm).

The head of normal sperm has an oval shape, a length of 3-5 $\mu \mathrm{m}$, a width of $2-3 \mu \mathrm{m}$ and is $1.5 \mu \mathrm{m}$ thick. It consists of the nucleus and the acrosome, which are covered by the nuclear membrane and the metacrosomic sheath. The nucleus contains the male genetic material. The DNA of the sperm has a slightly different structure from the DNA of a diploid (somatic) cell, meaning that the DNA is concentrated in the smallest possible volume, so as to save space. The acrosome contains proteolytic enzymes, such as acrosin, trypsin, hyaluronidase and proteases, which are released during the acrosome reaction and hydrolysis in granular cells and the zona pellucida of the egg in order to assist the penetration of the sperm and the merger with the $\operatorname{egg}(7)$.

The neck or mid-section of the sperm connects the head to the tail (length, $7.5 \mu \mathrm{m}$; and width, $1 \mathrm{~mm}$ ). It contains the axial filament surrounded by fibrils with circular layout and one to two centrosomes. The neck contains mitochondria, enzymes of glycolysis and oxidation systems and provides the necessary energy for survival and mobility.

The tail (length, 40-50 mm) consists of a total of ten pairs of fibrils (a central and nine peripheral) and is responsible for the typical sperm motility.

The sperm can survive for 3-5 days inside the vagina, particularly in the vagina or mucous membranes in the upper part of the female genital tract. Fertilization in this case is possible if the sperm remain alive. A single sperm is sufficient to fertilize the egg. Sperm survive outside the female body for up to several hours. When the sperm meets the oocyte, they swim around it. Subsequently, one of them adheres to the head of the oocyte and begins rotational movements about the longitudinal axis. The whole sperm then penetrates the oocyte, with the acrosome penetrating the egg cover [http://www.yourarticle library.com/biology/human-reproduction/structure-of-humansex-gametes-spermatozoan-and-ovum-biology/26913/; http:// www.onmed.gr/ygeia/story/329099/poso-zei-to-sperma-mesaston-kolpo\#ixzz44lwgUQgb (in Greek)].

\section{Molecules synthesized and secreted from the oocyte, which orient and stimulate sperm}

Resact (respiratory activating peptide) is a peptide of 14 amino acids, isolated from the egg jelly of the sea urchin, Arbacia punctulata (8). It is probably recognized by the guanylate cyclase (guanylate cyclase), a protein of the cell membrane of the sperm, which causes an increase in $\mathrm{Ca}^{2+}$ levels. Experimentally, when resact is added to a solution with spermatozoa, the latter undergoes helical movements directed towards the point of resact (http://worms.zoology.wisc.edu/dd2/echino/fert/chemotaxis/chemotaxis.html).

The sperm receptor for resact is a transmembrane protein. Once it binds resact on the extracellular side, it causes a conformational change on the cytoplasmic side, and it activates the receptor's enzymatic activity. This triggers the mitochondrial ATP-generating apparatus, as well as the dynein ATPase that stimulates flagellar movement in the sperm $(9,10)$.

Speract (sperm activating peptide) consists of ten amino acids and appears to promote the increase in $\mathrm{pH}$ and promotes sperm movement. The speract receptor is localized to the sperm tail (11), which contains the axoneme, the organelle of motility. The signaling in the sperm tail is central to motility regulation. There is evidence that speract can modulate sperm motility (12).

\section{The three stages of fertilization}

Sperm preparation: Capacitation and acrosome reaction. The phase of sperm maturation is known as activation (sperm capacitation). It occurs in the genital tract of the female, and acts as a preparatory step for the acrosome reaction. Activation does not include morphological changes and is accompanied by hyperactivation of the sperm which is a strong, non-linear motion (2). An important role is played by proteolytic enzymes (13).

In mammals, the ejaculated sperm is motile. However, their ability to fertilize an oocyte is reduced. The latter may occur after removing inhibitory factors, such as surface-attached glycoproteins, seminal plasma proteins and the depletion of membrane cholesterol. This final state of activated sperm is known as hyperactivation, and is a high energy phase of vigorous flagellar movement and swimming capacity (14).

Capacitation involves a number of processes, such as functional coupling of the signal transduction pathways that regulate the initiation of acrosome reactions by $\mathrm{ZP} 3$; alterations in flagellar motility that may be required to penetrate the zona pellucida; and the development of the capacity to fuse with eggs (15). The above-mentioned events are followed by alterations in metabolism, membrane biophysical characteristics, changes in the protein phosphorylation state, elevations in intracellular $\mathrm{pH}$ and calcium levels, and hyperpolarization of membrane potential. In vivo, many factors are likely to mediate the activation of sperm. Sterol binding proteins, such as high density lipoprotein, have been identified in the fallopian tubes and can accelerate the efflux of cholesterol from the sperm (16). Furthermore, progesterone can regulate some aspects of sperm activation. It is present in the environment of the fallopian tubes, derived both from follicular fluid and cells of the cumulus oophorus (17). Glucose is known to be essential for successful capacitation. It functions not only as an energy molecule allowing spermatozoa to swim, but it also enables the spermatozoa to fertilize eggs (18).

The agents of the oocyte mucous that cause the acrosome reaction are specific for each species. In mammals, sperm recognizes and binds to ZP3 glycoprotein of the zona pellucida. The O-polysaccharide connections to the core protein of ZP3 seem to be necessary in this step. It is believed that the terminal galactose of O-linked oligosaccharides reacts with 
galactosyltransferase $(\mathrm{Mr} 56 \mathrm{kDa})$, a cell membrane protein in the anterior end of the sperm head. The acrosome reaction of the sperm is caused by the core protein of ZP3. Once the core protein of ZP3 is damaged, this reaction is inhibited, but not the binding of the sperm to the zona pellucida. The sperm reaching the transparent zone is connected via SED1 protein to ZP3. As a result of irreversible binding of the sperm to the egg, the zona pellucida triggers the acrosome reaction.

The outer plasma membrane of the acrosome fuses at multiple sites with the plasma membrane and the contents of the acrosome are released. After the acrosome reaction, it is believed that the protein pre-acrosin of the acrosomal vesicle binds to ZP2, and becomes activated, forming the enzyme acrosin which digests the transparent area at this point. Digestion of the zona pellucida is followed by the fusion of the membrane of the sperm to the egg membrane, which seems to be caused by the PH-30 sperm protein (19).

$\mathrm{PH}-30$ is a transmembrane glycoprotein consisting of an $\alpha$ and $\beta$ subunit. The $\alpha$ subunit ( 289 amino acids) contains a sequence between 90 and 111 which has many similarities to the 'fusion peptide' E2 glycoprotein of the rubella virus. The $\beta$ subunit (353 amino acids) contains the tripeptide RGD (arginine-glycine-aspartic acid) in the last 90 amino acids of the N-terminus. The tripeptide RGD is the active site which can be recognized by integrins of the cell membrane of the egg. This recognition is followed by the fusion of the membranes, which is caused by the $\alpha$ subunit of PH-30. Both subunits derive from precursors that undergo proteolytic modification during the differentiation of sperm in the testes and their maturation in the epididymis. PH-30 is located in the cell membrane in the anterior portion of the side part of the mature sperm head $(19,20)$. The acrosome reaction involves the fusion of the acrosome membrane with the overlying plasma membrane of the sperm and vesicle formation. The result is the release of peptidases from the acrosomal vesicle that digest the mucous coat. The fusion of the membranes appears to be caused by the entry of $\mathrm{Ca}^{+2}$ ions and the exit of $\mathrm{K}^{+}$ions. The sperm plasma membrane that does not participate in the acrosome reaction and overlying the acrosome is known as the equatorial region. This seems to be the site of sperm and egg fusion (2). An acrosomal filament, is formed by the polymerization of $\mathrm{G}$ (Globular) actin to F (Fibrilar) actin. Desmin (30.5 kDa) is exposed to the acrosomal filament. The polymerization of actin is induced by the increase in $\mathrm{pH}(\sim 7.4)$, which results from the input of $\mathrm{Na}^{+}$and $\mathrm{H}^{+}$output. The activation of dynein ATPase and the use of ATP results in an increased movement of the sperm. cAMP levels increase (approximately 400 -fold) in the cytoplasm of sperm. This increase marks the beginning of the process of chromatin decondensation of the sperm, before the formation of the zygote nucleus.

P4 (progesterone) is a well-studied molecule involved in the modulation of sperm function. Its role in sperm capacitation has been revealed; however, the exact mechanisms involved are not yet fully understood. Progesterone is involved not only in capacitation, but also in other events, such as hyperactivated motility, flagellar bending, in chemotaxis, in acrosome reaction and in sperm-ZP binding and sperm-oocyte fusion. Its effects on sperm function have been studied in humans, as well as in other mammals (mouse, boar) (21-24).
Evans and Florman, in Nature Cell Biology and Nature Medicine (15), propose a model according to which in the sperm head, the receptor TPC2-ZP3 is triggered by its association with the zona pellucida. This results in calcium entry through T-type channels, leading to a transient increase in calcium levels in the cytoplasm and the activation of phospholipase C (PLC) via protein G. PLC is divided into IP3 and DAG. This causes $\mathrm{Ca}^{+}$entrance and leads to the acrosome reaction.

In the capacitation process, phosphatidyl-inositol-3kinase (PI3K) is phosphorylated/activated via a protein kinase A (PKA)-dependent cascade, and is downregulated by PKCa. At the beginning of capacitation, $\mathrm{PKCa}$ is active and results in PI3K inactivation. PKCa and PP1c2 are degraded by a PKA-dependent mechanism, and this allows the activation of PI3K. The activation of PKA, which depends on cAMP produced by the bicarbonate-dependent soluble adenylyl cyclase, leads to an increase in actin polymerization, an essential step so as to reach hyperactivated motility, which is necessary for successful fertilization (25).

The sperm-specific CatSper ion channels have been suggested to control the intracellular $\mathrm{Ca}^{2+}$ concentration and, thereby, the swimming behavior of spermatozoa (26). The CatSper channel seems to be activated by progesterone in human spermatozoa (29), which is interesting from the sperm-egg interaction viewpoint, as cumulus cells are known to produce progesterone (5).

Sperm-egg binding and fusion. The plasma membrane of the oocyte consists of two sites, a microvilli-free region and a microvilli-rich region. The fusion of sperm and oocyte takes place in the microvilli-rich region $(28,29)$. The interaction between sperm and oocyte is preceded by acrosomal exocytosis, triggered by sperm and ZP binding. It involves sperm attachment to the oocyte and cell-cell adhesion, leading to membrane fusion of the two gametes (30). The inner acrosomal membrane of the sperm, being exposed following the acrosome reaction, comes into contact with the oocyte membrane (31). The equatorial segment adheres to the posterior head of the sperm and fuses with the oocyte membrane $(32,33)$.

Several molecules have been identified in sperm and oocytes, with a crucial role in gamete binding. Fertilin $\alpha$, fertilin $\beta$ and cyritestin are also known as ADAM1, ADAM2 and ADAM3, respectively. Members of this family consist of a signal sequence domain, a metalloprotease domain, a disintegrin-like domain, a cysteine-rich domain and an epidermal growth factor-like repeat. A number of studies have revealed a role of ADAM1, ADAM2 and ADAM3 in sperm oocyte binding (30). Fertilin $\beta$ has been shown not to be essential for plasma membrane binding and fusion. Studies on fertilin $\beta$ and cyritestin with knockout mice have shown a reduced adhesion to the oocyte plasma membrane; however, some sperm adhere and they fuse with the oocyte $(15,34)$. Moreover, they show poor adhesion pattern to the ZP (34-36).

As regards oocytes, integrins found on the egg surface are thought to be receptors for sperm ADAMs. Studies have revealed that $\alpha 6 \beta 1$ integrin is an egg receptor for fertilin $\beta$ (37-39). Other studies have indicated that $\alpha 9 \beta 1$ integrin is a receptor for fertilin $\beta(40,41)$ CD46 has been found to be expressed in rodents on the acrosomal membrane of sperm (42). CD46 interacts directly with $\beta 1$ integrin and indirectly with tetraspanins 
in human cells (43). However, the key role of CD46 appears to stabilize the acrosomal membrane (44).

As an integrin-associated protein, in the oocyte, CD9 is essential for sperm-egg interactions. It is a member of a tetraspanin protein family expressed on the mouse egg surface (45). The role of CD9 in sperm oocyte fusion has been demonstrated in a number of studies with CD9-null oocytes which showed reduced ability for strong sperm adhesion (46). CD9-deficient mice show reduced fertility (47-49). Another tetraspanin member, CD81, is expressed on the oocyte surface and interacts with CD9 (50). Deletion of the CD81 gene results in a reduction in fertility. However, its role in sperm oocyte interaction has not yet been fully elucidated $(51,52)$.

CRISP1, a sperm protein expressed by the cumulus cells surrounding the oocyte, stimulates sperm orientation through the modulation of sperm hyperactivation and it seems to regulate CatSper (53). Recent studies have revealed an oocyte-derived chemotactic activity associated with a hydrophobic non-peptide molecule in human sperm (54) and an association between follicle rupture and uterine contractions with the success of human in vivo insemination, suggesting the existence of possible chemoattractive substances in the female tract (55). It is not clear if there is a binding partner on the oocyte membrane for sperm-associated CRISP protein, along with the exact mechanisms through which gamete binding is achieved.

The sperm-specific protein, Izumo, is essential for sperm-egg plasma membrane binding and fusion (56). IZUMO interacts directly with some molecules on the oolema. On the oocyte side, Juno is a member of the folate receptor family and recognizes the sperm IZUMO, facilitating fertilization. It has been revealed that mice lacking Juno on the surface of their egg cells are infertile as their egg cells do not fuse with normal sperm. This finding demonstrates the essential role of Juno in the fertility of female mice (57). Other studies have shown that a helical dimer of fragments of the $\mathrm{N}$-terminus domain of IZUMO is required for sperm-oocyte fusion (58). IZUMO forms complexes with other proteins on the sperm surface via its N-terminal domain which forms dimers (56). Therefore, IZUMO plays a key role in organizing and stabilizing a protein-like complex crucial for membrane fusion. Inoue et al (56) found a protein, angiotensin-converting enzyme 3 (ACE3) on the sperm acrosomal cap capable of interacting with IZUMO (59).

Studies have revealed the rapid loss of Juno from the oocyte membrane soon after fertilization. This implies that Juno is essential for the process of fertilization, thus, being the basis for polyspermy block in mammals. One possible explanation for this process is that Juno is shed in vesicles following fertilization, generating a zone of 'decoy oocyte' confined within the perivitelline space that could bind acrosome-reacted sperm and therefore avoid supernumerary sperm entry (60). Although it has been validated that Juno protein as the first cell surface receptor conserved in mammals, the interaction between IZUMO1 and Juno seems to be a necessary and an essential adhesion step; however, its role in the gamete fusion mechanism is not yet clear (57).

Two molecules, trypsin-like acrosin and spermosin proteases have been proposed to be involved in the first physical contact of the two gametes, suggesting that a proteasome system enables sperm to penetrate the chorion or participate in the process as sperm-related 'moveable' binding proteins (52). Sperm hyaluronidases are believed to play an intriguing role in fertilization in mammals, and sperm-specific SPAM1 and HYAL5 hyaluronidase have been suggested to be involved in sperm-ZP binding in mice. Recent studies have shown that hyaluronidases are not required for fertilization $(61,62)$.

It is important to mention that the oviductal environment and its secretions also play an essential role in the transport and interaction of male and female gametes. The expression of lactoferrin, a human oviductal protein, is able to inhibit gamete interaction in vitro and it seems to be involved in the regulation of the reproductive process through a role in polyspermy prevention (63). It has also been shown that lactoferrin causes a decrease in sperm $\alpha$-D-mannose binding sites and an increase in tyrosine phosphorylation of sperm proteins, thus implying that this protein is able to modulate the parameters of sperm function (64).

Cortical reaction: Meiosis resumption of oocyte and activation of the zygote. Once the sperm fuses with the oocyte, the beating of the tail stops immediately. The fusion of sperm and the oocyte membrane appears to cause the polymerization of actin and microvilli extension. The sperm instead is drawn into the oocyte by elongation and fusion of the microvilli of the egg. As a result, the sperm nucleus and other organelles are incorporated into the oocyte cytoplasm. The actin filaments are essential for the attraction of the sperm into the oocyte. The cytoplasm swells and forms colliculus $(\sim 7$ microns in length and 2 microns wide) resembling a so-called fertilization cone. In some invertebrates and amphibians, there are certain areas of the oocyte membrane for the binding and fusion of the sperm.

Seconds after fertilization, the membrane potential of the oocyte undergoes a large depolarization via a massive influx of $\mathrm{Na}^{+}$ions. The depolarization of the egg takes about a minute to repolarize via $\mathrm{K}^{+}$leakage. This is the fast block to polyspermy: sperm cannot fuse to a membrane that is not $-70 \mathrm{mV}$ (https://structureandfunction.wordpress.com/2013/02/28/thefast-and-slow-blocks-to-polyspermy-and-egg-activation/).

CG distribution and the cortical reaction following calcium oscillation are crucial steps in the prevention of polyspermy. Calcium released from the endoplasmic reticulum is dependent on the quality and quantity of the mitochondria, which are markers of oocyte quality, since a low mitochondrial DNA copy number results in poor oocyte developmental competence $(65,66)$.

PLC $\zeta$ from spermatozoa is considered to be the responsible activator during this process (67); however, other factors may also be involved $(5,68)$.

The cortical reaction is a process through which cortical granules from the oocyte are released preventing polyspermy. The fast block of polyspermy immediately prevents additional sperm getting attached to the oocyte. On the other hand, the cortical reaction establishes a permanent barrier to sperm entry and functions as the main part of the slow block of polyspermy in many animals. The cortical reaction is propagated over the surface of the egg by a wave of $\mathrm{Ca}^{++}$.

In this process, secretory vesicles located in the region below the plasma membrane of the oocyte, are fused with 


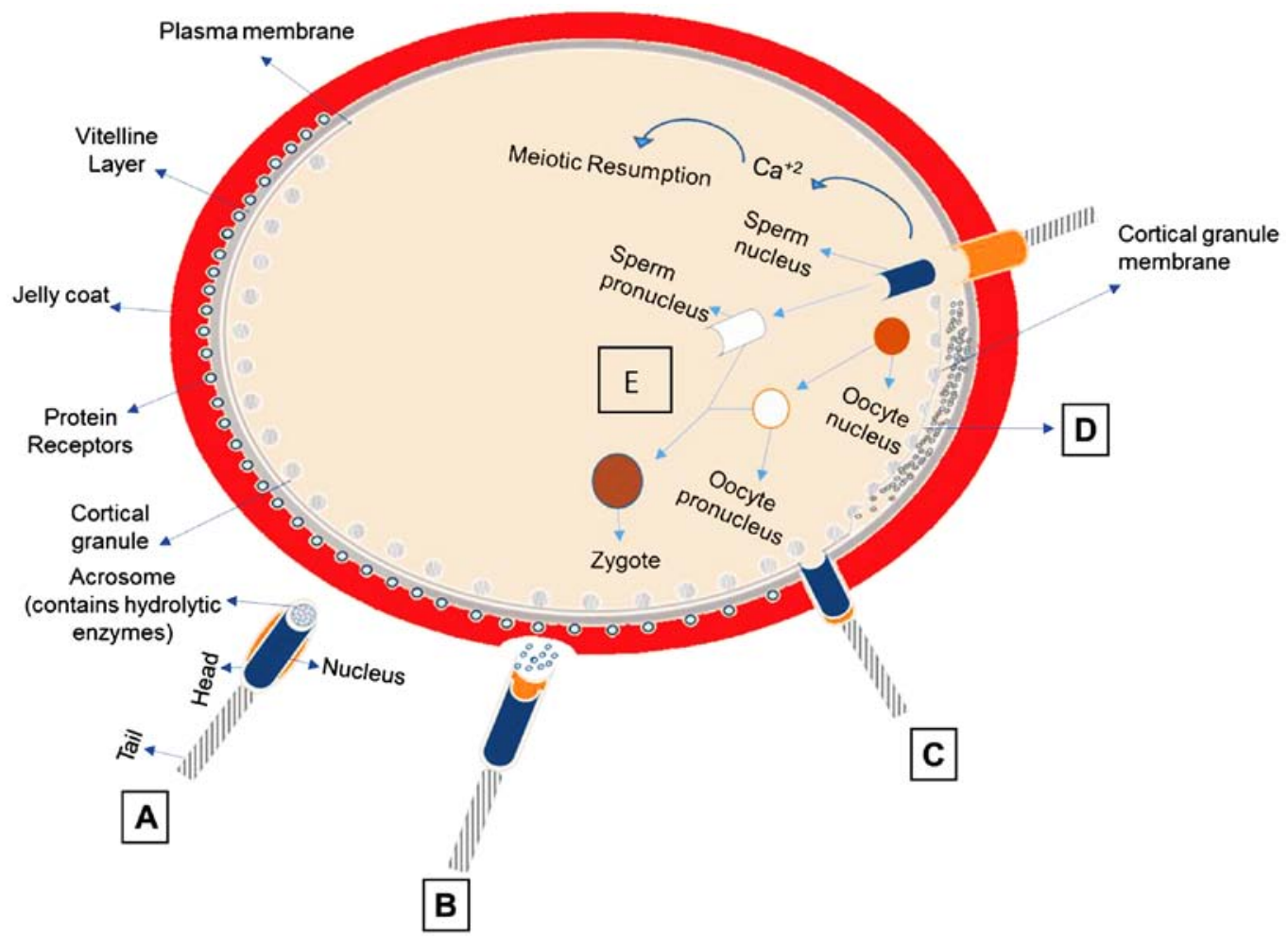

Figure 1. The events taking place in fertilization. (A) Sperm preparation-capacitation: Molecules (resact, speract) secreted from the oocyte, orient and stimulate sperm (guanylate cyclase). (B) Acrosome reaction: release of hydrolytic enzymes. The sperm via SED1 protein is connected to ZP3. (C) Fusion of sperm with plasma membrane of the oocyte: sperm pre-acrosin binds to ZP2. Proteins of sperm IZUMO, ADAMs 1, ADAMs 2, ADAMs 3 and CRISP1 bind to receptors on the oocyte (Juno, integrins, CD9, CD81). Other molecules identified playing role in gamete fusion are: Trypsin-like acrosin, spermosin, SPAM1, HYAL5, ACE3. (D) Cortical Reaction: $\mathrm{Ca}^{+2}$ release/wave of $\mathrm{Ca}^{+2}$ and formation of fertilization cone. Enzymes released by cortical granules, digest sperm receptors ZP2 and ZP3 (block of polyspermy). (E) Sperm chromatin decondensation to form male pronucleus: The oocyte nucleus completes the 2nd meiosis and eliminates the 2 nd polar body.

the oocyte plasma membrane. This results in the release of contents of the cortical granules, modifying the extracellular matrix so as to be impenetrable to other sperm. The cortical granules contain hydrolytic enzymes, such as proteases that clip perivitelline proteins, peroxidases that harden the vitelline envelope and glycosaminoglycans that attract water into the perivitelline space, causing it to expand and form the hyaline layer. Calcium ions from the cortical smooth endoplasmic reticulum are responsible for cortical granule rupture. It is believed that this is provoked by the activation of a G-protein in the plasma membrane of the oocyte. The sperm binds to ZP3 which is consistent with the G-protein and becomes active. Bindin binds the sperm to the oocyte cell membrane, but another sperm factor activates a receptor, which in turn activates the G-protein. G-proteins of the spermatozoon itself (activated when sperm was in contact with the mucous of the egg shell with the initiation of the acrosome reaction) activate enzymes, which results in increased $\mathrm{Ca}^{+2}$ levels in the egg.

In mammals, the cortical reaction modifies the zona pellucida, leading to the block of polyspermy. Several enzymes are released by the cortical granules, leading to the digestion of the sperm receptor glycoproteins ZP2 and ZP3, so that they can no longer bind spermatozoon (https://en.wikipedia.org/ wiki/Cortical_reaction).

It is interesting to know hows sperm factor causes the release of $\mathrm{Ca}^{+2}$. Activated G-protein activates the enzyme, PLC. The latter cleaves the lipid phosphotidylinositol 4,5-biphosphate (PIP2) in diacyglycerol (DAG) and inositol 1,4,5-triphosphate (IP3). PIP2 and DAG are second messengers. IP3 binds to its receptors in the endoplasmic reticulum, at the entry point of the sperm. This results in the release of $\mathrm{Ca}^{+2}$ from the endoplasmic reticulum at this point. $\mathrm{Ca}^{+2}$ ions bind to sensitive $\mathrm{Ca}^{+2}$ receptors in the endoplasmic reticulum around the cortical granules. $\mathrm{Ca}^{+2}$ binding to these receptors results in the release of more $\mathrm{Ca}^{+2}$, which spreads like a wave in the region (cortex) of the egg and causes the rupture of cortical granules. DAG activates PKC which phosphorylates protein exchange ions $\mathrm{Na}^{+}$to $\mathrm{H}^{+}$. The protein that exchanges ions, is activated by $\mathrm{Ca}^{+2}$ and the result of this activation is the entrance to $\mathrm{Na}^{+}$and $\mathrm{H}^{+}$output and an increase in $\mathrm{pH}$ from 6.8 to 7.3 in the egg. This 'wakes up' the oocyte from the metabolic inertia (69).

The last phase of oocyte activation is the resumption and completion of meiosis. This leads to polar body extrusion, cleavage of the zygote and embryonic cell divisions. There are widespread changes in molecules, such as proteins and RNAs that are not necessarily involved in meiosis resumption. Changes in proteomes and their composition have been revealed, showing significant degradation of maternal proteins. This is due to protein degradation, phosphorylation, post-translational modifications and new translation of maternal RNAs (70).

Cytoplasmic polyadenylation involves the elongation of the poly(A) tail after the export of mRNAs to the cytoplasm. It has been observed and described in the oocytes and early embryos of many animal species, from invertebrates to mammals, and 
is universally considered to be a regulatory mechanism for protein expression from specific mRNAs. The mediators of this process (cytoplasmic polyadenylation elements and their binding proteins) have been described in detail and some new findings have been reviewed recently $(71,72)$.

The sperm nucleus undergoes a series of changes, including chromatin decondensation and the formation of a new nuclear envelope, to form the male pronucleus. The latter uses microtubules to migrate to the center of the cell, where it fuses with the female pronucleus to form a diploid nucleus. Other sperm organelles (e.g., mitochondria) persist during the early cleavage stages of the embryo and they may play a role in development (19).

The beginning, condensation of chromatin seems to happen with two histone phosphorylations of the sperm and their exchange with histones of the oocyte. Chromatin is condensed following interaction with histones $\mathrm{H} 3$ and $\mathrm{H} 4$, and $\mathrm{X}$ and $\mathrm{Y}$ sperm-specific proteins. In the cytoplasm of the ovum is the protein nycleoplasmin connected with histones $\mathrm{H} 2 \mathrm{~A}$ and $\mathrm{H} 2 \mathrm{~B}$. As nucleoplasmin has greater affinity for the $\mathrm{X}$ and $\mathrm{Y}$ sperm proteins, the exchange of histones $\mathrm{H} 2 \mathrm{~A} / \mathrm{H} 2 \mathrm{~B}$ with $\mathrm{X}$ and $\mathrm{Y}$ proteins occurs. This exchange allows the de-concentration and sharpness of the chromatin nucleus of the sperm. The process of decompression begins from the periphery to the center of the nucleus. When this process is finished, the vesicles of the nuclear membrane of the sperm bind to vesicles from the endoplasmic reticulum of the egg. The membrane of the pronucleus of the sperm is produced. While the pro nucleus of the sperm is formed, the nucleus of the oocyte completes the second division of meiosis and eliminates the second polar body. After entering the oocyte, the nucleus and the sperm centrosome rotate $180^{\circ}$, so that the centrosome is positioned between the nucleus of the sperm and ovum. The centrosome organizes microtubules that attach and pull the pronucleus of the sperm and the egg. Both pronuclei migrate towards each other and they are directed towards the center of the cytoplasm of the ovum. The membranes of the two pronuclei rupture and mixing of nuclear material is observed, resulting in the formation of the diploid nucleus of the zygote. The fusion of the pronuclei occurs in $<1 \mathrm{~h}$ e.g., in Echinus (the meiotic division is finished before ovulation). Approximately $12 \mathrm{~h}$ in mammals including most eggs (e.g., human) is needed to complete the second division of meiosis with the excretion of the second polar body (73). Fig. 1 illustrates the events taking place in fertilization.

\section{Reorganization and partition of the zygote}

Once the sperm enters the oocyte, the cytoplasmic material is reorganized. The cytoplasm of the oocyte contains cytoplasmic determinants that become distributed on different cells during cleavage. The cytoplasmic determinants (e.g., $\mathrm{Vg} 1$ and bicoid) directly or indirectly activate or inactivate genes and control events of differentiation in an early embryo. The point through which sperm has penetrated the oocyte marks the bilateral symmetry of the future adult organism. Following fertilization, cortical rotation occurs. Tubulin microtubules are organized as train tracks between the cortical and the endoplasm in the vegetal pole. The result is the appearance of a gray area, the gray crescent, which marks the future dorsal side of the embryo. Between the midpoint of the gray crescent and the entry point of sperm is the level of the lateral symmetry normally marked with the first cleavage.

The gray crescent is a region of zygote in which early morphogenetic movements will begin to form the blastopore, which marks the beginning of the process of gastrulation in the early embryo. Following fertilization, a sequence of cell divisions results in the formation of the early embryo. The zygote begins to divide mitotically (cleavage), and the resulting cells are termed blastomeres. As long as cleavage progresses, the cells proliferate and become progressively smaller, and the fetal size and general shape remains the same (73).

The first cleavage begins as 'a ring' (cleavage furrow) around the zygote and is parallel to the polar axis (animal-vegetal pole) of the zygote and normal to the longitudinal axis (axis joining the poles of the spindle) of the mitotic spindle. The ring consists of actin-myosin found in the cortical separating the zygote inwardly. The myosin plays the role of ATPase and controls the actin. The level of the second cleavage is parallel to the polar axis. At this stage, the embryo consists of four blastomeres, extending from the animal to the vegetal pole. Cleavage is a fractionating process, resulting in the formation of an eight -cell stage and in a 16-32 cell so-called morula (69).

\section{Fertilization failure}

Some fertility issues may arise from failure in fertilization events, in the molecular base, described in this review. Defects in the expression of receptors in the oocyte cell membrane (e.g., CD9), destruction of the gamete fusion mechanism, insufficient or abnormal variation of $\mathrm{Ca}^{2+}$ and failure of exocytosis of cortical granules, inadequate completion of second meiotic division of the oocyte, defective sperm chromatin decondensation, defective pronucleus due to abnormal remodeling of chromatin (multiple pronuclei) or abnormal formation/function of the mitotic spindle, may account for infertility.

\section{References}

1. Wassarman PM and Florman HM: Cellular mechanisms during mammalian fertilization. In: Handbook of Physiology: Section 14-Cell Physiology. Oxford University Press, New York, NY, pp885-938, 1997.

2. Yanagimachi R: The Physiology of Reproduction. Raven Press, New York, NY, pp189-317, 1994.

3. Jin M, Fujiwara E, Kakiuchi Y, Okabe M, Satouh Y, Baba SA, Chiba K and Hirohashi N: Most fertilizing mouse spermatozoa begin their acrosome reaction before contact with the zona pellucida during in vitro fertilization. Proc Natl Acad Sci USA 108: 4892-4896, 2011.

4. Tokuhiro K, Ikawa M, Benham AM and Okabe M: Protein disulfide isomerase homolog PDILT is required for quality control of sperm membrane protein ADAM3 and male fertility [corrected]. Proc Natl Acad Sci USA 109: 3850-3855, 2012.

5. Okabe M: The cell biology of mammalian fertilization. Development 140: 4471-4479, 2013.

6. Zuccotti M, Piccinelli A, Giorgi Rossi P, Garagna S and Redi CA: Chromatin organization during mouse oocyte growth. Mol Reprod Dev 41: 479-485, 1995.

7. Nelson L: Enzymes associated with sperm cell function. In: Biology of Fertilization. Metz CB and Monroy A (eds). London Academic Press, Orlando, FL, pp215-131, 1985.

8. Ward GE, Brokaw CJ, Garbers DL and Vacquier VD: Chemotaxis of Arbacia punctulata spermatozoa to resact, a peptide from the egg jelly layer. J Cell Biol 101: 2324-2329, 1985.

9. Shimomura H, Dangott LJ and Garbers DL: Covalent coupling of a resact analogue to guanylate cyclase. J Biol Chem 261: 15778-15782, 1986. 
10. Cook SP and Babcock DF: Selective modulation by cGMP of the $\mathrm{K}^{+}$channel activated by speract. J Biol Chem 268: 22402-22407, 1993.

11. Cardullo RA, Herrick SB, Peterson MJ and Dangott LJ: Speract receptors are localized on sea urchin sperm flagella using a fluorescent peptide analog. Dev Biol 162: 600-607, 1994.

12. Cook SP, Brokaw CJ, Muller CH and Babcock DF: Sperm chemotaxis: Egg peptides control cytosolic calcium to regulate flagellar responses. Dev Biol 165: 10-19, 1994.

13. Talbot $P$ and Franklin LE: Surface modification of guinea pig sperm during in vitro capacitation: An assessment using lectin-induced agglutination of living sperm. J Exp Zool 203: 1-14, 1978.

14. Lishko PV, Kirichok Y, Ren D, Navarro B, Chung JJ and Clapham DE: The control of male fertility by spermatozoan ion channels. Annu Rev Physiol 74: 453-475, 2012.

15. Evans JP and Florman HM: The state of the union: the cell biology of fertilization. Nat Cell Biol 4: s57-s63, 2002.

16. Visconti PE, Ning X, Fornés MW, Alvarez JG, Stein P, Connors SA and Kopf GS: Cholesterol efflux-mediated signal transduction in mammalian sperm: Cholesterol release signals an increase in protein tyrosine phosphorylation during mouse sperm capacitation. Dev Biol 214: 429-443, 1999.

17. Contreras HR and Llanos MN: Detection of progesterone receptors in human spermatozoa and their correlation with morphological and functional properties. Int J Androl 24: 246-252, 2001

18. Goodson SG, Qiu Y, Sutton KA, Xie G, Jia W and O'Brien DA: Metabolic substrates exhibit differential effects on functional parameters of mouse sperm capacitation. Biol Reprod 87: 75, 2012.

19. Blobel CP, Myles DG, Primakoff P and White JM: Proteolytic processing of a protein involved in sperm-egg fusion correlates with acquisition of fertilization competence. J Cell Biol 111: $69-78,1990$

20. Primakoff $\mathrm{P}$, Hyatt $\mathrm{H}$ and Tredick-Kline $\mathrm{J}$ : Identification and purification of a sperm surface protein with a potential role in sperm-egg membrane fusion. J Cell Biol 104: 141-149, 1987.

21. López-Torres AS and Chirinos M: Modulation of human sperm capacitation by progesterone, estradiol, and luteinizing hormone. Reprod Sci 12: 1-9, 2016

22. Roldan ER, Murase T and Shi QX: Exocytosis in spermatozoa in response to progesterone and zona pellucida. Science 266 $1578-1581,1994$

23. Wu JT, Chiang KC and Cheng FP: Expression of progesterone receptor(s) during capacitation and incidence of acrosome reaction induced by progesterone and zona proteins in boar spermatozoa. Anim Reprod Sci 93: 34-45, 2006.

24. de Lamirande E, Harakat A and Gagnon C: Human sperm capacitation induced by biological fluids and progesterone, but not by NADH or NADPH, is associated with the production of superoxide anion. J Androl 19: 215-225, 1998.

25. Ickowicz D, Finkelstein M and Breitbart H: Mechanism of sperm capacitation and the acrosome reaction: Role of protein kinases. Asian J Androl 14: 816-821, 2012.

26. Chang $\mathrm{H}$ and Suarez SS: Two distinct $\mathrm{Ca}(2+)$ signaling pathways modulate sperm flagellar beating patterns in mice. Biol Reprod 85: 296-305, 2011.

27. Brenker C, Goodwin N, Weyand I, Kashikar ND, Naruse M, Krähling M, Müller A, Kaupp UB and Strünker T: The CatSper channel: A polymodal chemosensor in human sperm. EMBO J 31: 1654-1665, 2012.

28. Ebensperger $C$ and Barros C: Changes at the hamster oocyte surface from the germinal vesicle stage to ovulation. Gamete Res 9: 387-397, 1984

29. Johnson MH, Eager D, Muggleton-Harris A and Grave HM: Mosaicism in organisation concanavalin A receptors on surface membrane of mouse egg. Nature 257: 321-322, 1975.

30. Evans JP: The molecular basis of sperm-oocyte membrane interactions during mammalian fertilization. Hum Reprod Update 8: 297-311, 2002

31. Huang TTF Jr and Yanagimachi R: Inner acrosomal membrane of mammalian spermatozoa: Its properties and possible functions in fertilization. Am J Anat 174: 249-268, 1985.

32. Yanagimachi R and Noda YD: Physiological changes in the postnuclear cap region of mammalian spermatozoa: A necessary preliminary to the membrane fusion between sperm and egg cells. J Ultrastruct Res 31: 486-493, 1970.

33. Bedford JM, Moore HDM and Franklin LE: Significance of the equatorial segment of the acrosome of the spermatozoon in eutherian mammals. Exp Cell Res 119: 119-126, 1979.
34. Cho C, Bunch DO, Faure JE, Goulding EH, Eddy EM, Primakoff $\mathrm{P}$ and Myles DG: Fertilization defects in sperm from mice lacking fertilin $\beta$. Science 281: 1857-1859, 1998.

35. Shamsadin R, Adham IM, Nayernia K, Heinlein UAO, Oberwinkler $\mathrm{H}$ and Engel W: Male mice deficient for germ-cell cyritestin are infertile. Biol Reprod 61: 1445-1451, 1999.

36. Nishimura H, Cho C, Branciforte DR, Myles DG and Primakoff P: Analysis of loss of adhesive function in sperm lacking cyritestin or fertilin beta. Dev Biol 233: 204-213, 2001.

37. Almeida EA, Huovila AP, Sutherland AE, Stephens LE, Calarco PG, Shaw LM, Mercurio AM, Sonnenberg A, Primakoff P, Myles DG and White JM: Mouse egg integrin $\alpha 6$ $\beta 1$ functions as a sperm receptor. Cell 81: 1095-1104, 1995.

38. Chen MS, Tung KS, Coonrod SA, Takahashi Y, Bigler D, Chang A, Yamashita Y, Kincade PW, Herr JC and White JM: Role of the integrin-associated protein CD9 in binding between sperm ADAM 2 and the egg integrin $\alpha 6 \beta 1$ : Implications for murine fertilization. Proc Natl Acad Sci USA 96: 11830-11835, 1999.

39. Chen H and Sampson NS: Mediation of sperm-egg fusion: Evidence that mouse egg $\alpha 6 \beta 1$ integrin is the receptor for sperm fertilinbeta. Chem Biol 6: 1-10, 1999.

40. Eto K, Huet C, Tarui T, Kupriyanov S, Liu HZ, Puzon-McLaughlin W, Zhang XP, Sheppard D, Engvall E and Takada Y: Functional classification of ADAMs based on a conserved motif for binding to integrin $\alpha 9 \beta$ 1: Implications for sperm-egg binding and other cell interactions. J Biol Chem 277: 17804-17810, 2002.

41. Zhu X and Evans JP: Analysis of the roles of RGD-binding integrins, $\alpha(4) / \alpha(9)$ integrins, $\alpha(6)$ integrins, and CD9 in the interaction of the fertilin $\beta$ (ADAM2) disintegrin domain with the mouse egg membrane. Biol Reprod 66: 1193-1202, 2002.

42. Mizuno M, Harris CL, Johnson PM and Morgan BP: Rat membrane cofactor protein (MCP; CD46) is expressed only in the acrosome of developing and mature spermatozoa and mediates binding to immobilized activated C3. Biol Reprod 71: 1374-1383, 2004.

43. Lozahic S, Christiansen D, Manié S, Gerlier D, Billard M, Boucheix C and Rubinstein E: CD46 (membrane cofactor protein) associates with multiple betal integrins and tetraspans. Eur J Immunol 30: 900-907, 2000

44. Johnson PM, Clift LE, Andrlíková P, Jursová M, Flanagan BF, Cummerson JA, Stopka P and Dvorakova-Hortova K: Rapid sperm acrosome reaction in the absence of acrosomal CD46 expression in promiscuous field mice (Apodemus). Reproduction 134: 739-747, 2007.

45. Stein KK, Primakoff P and Myles D: Sperm-egg fusion: Events at the plasma membrane. J Cell Sci 117: 6269-6274, 2004

46. Jégou A, Ziyyat A, Barraud-Lange V, Perez E, Wolf JP, Pincet F and Gourier C: CD9 tetraspanin generates fusion competent sites on the egg membrane for mammalian fertilization. Proc Natl Acad Sci USA 108: 10946-10951, 2011.

47. Kaji K, Oda S, Shikano T, Ohnuki T, Uematsu Y, Sakagami J, Tada N, Miyazaki S and Kudo A: The gamete fusion process is defective in eggs of Cd9-deficient mice. Nat Genet 24: 279-282, 2000.

48. Le Naour F, Rubinstein E, Jasmin C, Prenant M and Boucheix C: Severely reduced female fertility in CD9-deficient mice. Science 287: 319-321, 2000.

49. Miyado K, Yamada G, Yamada S, Hasuwa H, Nakamura Y, Ryu F, Suzuki K, Kosai K, Inoue K, Ogura A, et al: Requirement of CD9 on the egg plasma membrane for fertilization. Science 287: $321-324,2000$.

50. Horváth G, Serru V, Clay D, Billard M, Boucheix C and Rubinstein E: CD19 is linked to the integrin-associated tetraspans CD9, CD81, and CD82. J Biol Chem 273: 30537-30543, 1998.

51. Takahashi Y, Bigler D, Ito Y and White JM: Sequence-specific interaction between the disintegrin domain of mouse ADAM 3 and murine eggs: Role of beta1 integrin-associated proteins CD9, CD81, and CD98. Mol Biol Cell 12: 809-820, 2001.

52. Rubinstein E, Ziyyat A, Prenant M, Wrobel E, Wolf JP, Levy S, Le Naour F and Boucheix C: Reduced fertility of female mice lacking CD81. Dev Biol 290: 351-358, 2006.

53. Ernesto JI, Weigel Muñoz M, Battistone MA, Vasen G, Martínez-López P, Orta G, Figueiras-Fierro D, De la Vega-Beltran JL, Moreno IA, Guidobaldi HA, et al: CRISP1 as a novel CatSper regulator that modulates sperm motility and orientation during fertilization. J Cell Biol 210: 1213-1224, 2015. 
54. Armon L, Ben-Ami I, Ron-El R and Eisenbach M: Human oocyte-derived sperm chemoattractant is a hydrophobic molecule associated with a carrier protein. Fertil Steril 102: 885-890, 2014

55. Blasco V, Prados N, Carranza F, González-Ravina C, Pellicer A and Fernández-Sánchez M: Influence of follicle rupture and uterine contractions on intrauterine insemination outcome: A new predictive model. Fertil Steril 102: 1034-1040, 2014.

56. Inoue N, Ikawa M, Isotani A and Okabe M: The immunoglobulin superfamily protein Izumo is required for sperm to fuse with eggs. Nature 434: 234-238, 2005.

57. Bianchi E, Doe B, Goulding D and Wright GJ: Juno is the egg Izumo receptor and is essential for mammalian fertilization. Nature 508: 483-487, 2014

58. Inoue N, Hamada D, Kamikubo H, Hirata K, Kataoka M, Yamamoto M, Ikawa M, Okabe M and Hagihara Y: Molecular dissection of IZUMO1, a sperm protein essential for sperm-egg fusion. Development 140: 3221-3229, 2013.

59. Inoue N, Kasahara T, Ikawa $\mathrm{M}$ and Okabe M: Identification and disruption of sperm-specific angiotensin converting enzyme-3 (ACE3) in mouse. PLoS One 5: e10301, 2010.

60. Bianchi E and Wright GJ: Izumo meets Juno: Preventing polyspermy in fertilization. Cell Cycle 13: 2019-2020, 2014

61. Sawada H, Mino M and Akasaka M: Sperm proteases and extracellular ubiquitin-proteasome system involved in fertilization of ascidians and sea urchins. Adv Exp Med Biol 759: $1-11,2014$.

62. Zhou C, Kang W and Baba T: Functional characterization of double-knockout mouse sperm lacking SPAM1 and ACR or SPAM1 and PRSS21 in fertilization. J Reprod Dev 58: 330-337, 2012.

63. Yoon S, Chang KT, Cho H, Moon J, Kim JS, Min SH, Koo DB, Lee SR, Kim SH, Park KE, et al: Characterization of pig sperm hyaluronidase and improvement of the digestibility of cumulus cell mass by recombinant pSPAM1 hyaluronidase in an in vitro fertilization assay. Anim Reprod Sci 150: 107-114, 2014.
64. Zumoffen CM, Gil R, Caille AM, Morente C, Munuce MJ and Ghersevich SA: A protein isolated from human oviductal tissue in vitro secretion, identified as human lactoferrin, interacts with spermatozoa and oocytes and modulates gamete interaction. Hum Reprod 28: 1297-1308, 2013.

65. Zumoffen CM, Massa E, Caille AM, Munuce MJ and Ghersevich SA: Effects of lactoferrin, a protein present in the female reproductive tract, on parameters of human sperm capacitation and gamete interaction. Andrology 3: 1068-1075, 2015.

66. Tosti $\mathrm{E}$ and Ménézo Y: Gamete activation: Basic knowledge and clinical applications. Hum Reprod Update 22: 420-439, 2016.

67. Nomikos M, Swann K and Lai FA: Starting a new life: sperm PLC-zeta mobilizes the Ca2+ signal that induces egg activation and embryo development: an essential phospholipase $\mathrm{C}$ with implications for male infertility. BioEssays 34: 126-134, 2012.

68. Harada Y, Kawazoe M, Eto Y, Ueno S and Iwao Y: The Ca2+ increase by the sperm factor in physiologically polyspermic newt fertilization: Its signaling mechanism in egg cytoplasm and the species-specificity. Dev Biol 351: 266-276, 2011.

69. Abbott ALand Ducibella T: Calcium and the control of mammalian cortical granule exocytosis. Front Biosci 6: D792-D806, 2001.

70. Krauchunas AR and Wolfner MF: Molecular changes during egg activation. Curr Top Dev Biol 102: 267-292, 2013.

71. Charlesworth A, Meijer HA and de Moor CH: Specificity factors in cytoplasmic polyadenylation. Wiley Interdiscip Rev RNA 4 437-461, 2013.

72. Sousa Martins JP, Liu X, Oke A, Arora R, Franciosi F, Viville S, Laird DJ, Fung JC and Conti M: DAZL and CPEB1 regulate mRNA translation synergistically during oocyte maturation. J Cell Sci 129: 1271-1282, 2016.

73. Gilbert SF (ed): Developmental Biology. 10th edition. Sinauer Associates. Sunderlan, 2013. 